\title{
Genetic Diversity in Indigenous Landraces of Brassica napus based on Morphological and Biochemical Characteristics using Multivariate Techniques
}

\author{
Naushad Ali ${ }^{1}$, Naqib Ullah Khan²*, Farhatullah², Malik Ashiq Rabbani ${ }^{3}$, Zarina Bibi ${ }^{4}$, Samrin Gul ${ }^{2}$, Sardar Ali ${ }^{1}$, Shah \\ Masaud Khan', Ijaz Hussain ${ }^{1}$, Izhar Hussain ${ }^{1}$ and Khalid Naveed ${ }^{1}$ \\ ${ }^{1}$ Department of Agricultural Sciences, University of Haripur, Haripur - Pakistan \\ ${ }^{2}$ Department of Plant Breeding and Genetics, The University of Agriculture, Peshawar - Pakistan \\ ${ }^{3}$ Plant Genetic Resources Institute (PGRI), NARC, Islamabad - Pakistan \\ ${ }^{4}$ Institute of Soil Science, Chinese Academy of Sciences (CAS), Nanjing - China \\ *For correspondence: nukmarwat@yahoo.com; nukmarwat@aup.edu.pk
}

\begin{abstract}
In order to assess genetic diversity of Brassica napus L., the seventy indigenous landraces along with two check cultivars (Shiralee and Pakola) were collected from different regions of Pakistan. The said germplasm was evaluated for 25 morphological and biochemical traits under field conditions during 2012 and 2013 at University of Haripur, Pakistan. Significant genotypic variability was observed among the tested landraces of B. napus for majority of traits during both years of studies. Among B. napus germplasm, the foremost genetic variability producing traits were, plant height and maturity, while adequate variations were recorded for flower initiation and completion, main raceme length and silique per main raceme and glucosinolate content. During 2012, cluster analysis divided the total 70 landraces of $B$. napus into nine main groups and contribution of five principal components (PCs) was 14.13, 13.11, 10.55, 9.85 and 8.25\%, respectively. However, during 2013, the genotypes were categorized in seven main groups and the contribution of five PCs was 22.54, 16.69, 7.91, 6.54 and $6.11 \%$, respectively. Based on two year studies, genotypes i.e., 24876, 24864, 24866 and 24901 were found promising with maximum genetic diversity and may be selected for future breeding program.@ 2018 Friends Science Publishers
\end{abstract}

Keywords: Brassica; Cluster analysis; Earliness; Genetic diversity; Principal component analysis

\section{Introduction}

Germplasm of a specific crop collected from the diverse sources offers greater genetic diversity and may furnish useful traits to widen the genetic base of the crop species. The success in the improvement of crops both qualitatively and quantitatively and the development of a crop species requires the availability and accessibility of genetic diversity. Knowing of duplicates, organization of core collection of a particular population and the selection of parental lines for development of new cultivars are directly related to the genetic diversity (Jatoi et al., 2011; Yousaf et al., 2011; Zada et al., 2013).

The family Brassicaceae contains about 350 genera and 3500 species, and is one of the 10 most economically important plant families with a wide range of agronomic traits (Rich, 1991; Love et al., 2005). Brassica napus L. (AACC, $2 \mathrm{n}=38$ ) is a comparatively new species that originated in a limited geographic region through spontaneous hybridizations between turnip rape (B. rapa $\mathrm{L}$. AA, $2 n=20)$ and cabbage $($ B. oleracea L. CC, $2 n=18)$ genotypes (Kimber and McGregor, 1995). Composition of oil and protein in the seed of mustard (B. juncea L. AABB, $2 \mathrm{n}=36$ ) and rapeseed (B. rapa $\mathrm{L}$. and B. napus $\mathrm{L}$.) is $42 \%$ and $25 \%$, respectively.

Brassica oil is composed of unsaturated fatty acids and contains fat-soluble vitamins A,D, E and K. After extraction of oil, the oilcake contains proteins of high biological value and applicable quantities of calcium and phosphorus, which is a good source for animal feeding and fertilizer for crops. Among oilseed crops, rapeseed and mustard ranks third in terms of area and production after soybean and cotton (Islam and Islam, 2000; Ali et al., 2015). Today, oilseed rape is the most important source of vegetable oil in Europe and the second most important oilseed crop in the world after soybean. However, its limited geographic range and intensive breeding has led to a relatively narrow genetic base. The gene pool of elite oilseed rape breeding material has been further eroded by an emphasis on specific oil and seed quality traits. Consequently, genetic variability in this important crop is restricted with regard to many characters of value for breeding purposes (Khan et al., 2013).

To cite this paper: Ali, N., N.U. Khan, Farhatullah, M.A. Rabbani, Z. Bibi, S. Gul, S. Ali, S.M. Khan, I. Hussain, I. Hussain and K. Naveed, 2018. Genetic diversity in indigenous landraces of Brassica napus based on morphological and biochemical characteristics using multivariate techniques. Int. J. Agric. Biol., 20: $277-287$ 
Due to the presence of undesirable long chain fatty acids like erucic acid in the seed oil, it becomes unfavorable to human health. Erucic acid increases blood cholesterol, interferes in myocardial conductance and shortens coagulation time. European economic committee has restricted cultivation of Brassica crop that contains more than 5\% erucic acid content in their oil (Zada et al., 2013). Several plant breeders throughout the world introduced canola type cultivars by using selection, mutation, conventional breeding and modern biotechnological techniques (Chen et al., 1988). Both linoleic and linolenic acids are essential fatty acids; however, less than 3\% linolenic acid is preferred for oil stability.

Like any other crop species, the first step in Brassica improvement is evaluation of all the available landraces, including collection, evaluation and molecular characterization of germplasm lines. On average, the locally collected brassica genotypes are more resistant to various biotic and abiotic stresses than already released improved cultivars (Zada et al., 2013). Knowledge about germplasm diversity and genetic relationship could be a valuable aid in crop improvement strategies.

Presently, several important methods are used to assess genetic variability in various crop populations. These methods rely on the data of pedigree, agronomic, morphological, and biochemical traits and more recently the molecular data (Mohammadi and Prasanna, 2003). Precise evaluation of the patterns of genetic diversity can be invaluable in crop breeding for diverse applications such as analysis of genetic variability in cultivars (Turi et al., 2012), recognizing different parental combinations and introgression of desirable genes from diverse germplasm into the available genetic base (Thompson et al., 1998). Genetic distance among canola cultivars was estimated through multivariate analysis, and 30 cultivars from various sources were analyzed and clustered based upon five morphological and yield traits i.e., crown diameter, branches per plant, pods per plant, seeds per pod and yield per plant and placed in three distinct clusters (Ali et al., 1995). Keeping in view the importance of B. napus L., an attempt was made to determine the genetic diversity in indigenous landraces based on morphological and biochemical characteristics using multivariate techniques.

\section{Materials and Methods}

\section{Germplasm and Experimental Procedure}

Seventy genotypes including 68 indigenous landraces and two check cultivars i.e., Shiralee and Pakola of Brassica napus L. were collected from different regions of four provinces, FATA and Gilgit - Baltistan, Pakistan (Table 1). The said germplasm was evaluated for 25 morphological and biochemical traits under field conditions during 2012 and 2013 at University of Haripur, -Pakistan. Each accession was sown in 2 rows of $5 \mathrm{~m}$ length in the $3^{\text {rd }}$ week of September during 2012 and 2013. Row to row and plant to plant spacing was kept at 45 and $10 \mathrm{~cm}$, respectively. Planting of the experiments was done with hand drill and thinning was done after two weeks of germination to maintain optimum plant population. Weeds were controlled manually. Recommended cultural practices and inputs were applied uniformly to all entries during both growing seasons to minimize the field environmental variations. In both seasons, the harvesting was made during first week of March.

\section{Traits Measurement}

Data were recorded on 10 randomly selected plant for various traits i.e., days to flower initiation, days to $50 \%$ flowering, days to flower completion, days to maturity, leaf petiole length, leaf length, leaf width, leaf width length ratio, leaves per plant, plant height, length of main racemes, silique main per raceme, silique length, silique width, seeds per silique, 1000 seed weight and seed yield per plant. Trait selection and measurement techniques were based on IPGRI descriptors of Brassica and Raphanus (Table 2). Bulked seed samples from each accession were analyzed to determine fatty acids composition using Near-Infrared Spectroscopy (NIRS) (FOSS NIR Systems Model 6500) equipped with ISI version 1.02 a software of Infra Soft International according to the manufacturer's protocol. A sample size of 2 to $5 \mathrm{~g}$ seed was used for biochemical analysis. Analysis of oil content (\%), protein content (\%), glucosinolates content $\left(\mu \mathrm{M} \mathrm{g}^{-1}\right)$, oleic acid $(\%)$, linolenic acid (\%) and erucic acid content (\%) was carried out at Nuclear Institute for Food and Agriculture (NIFA), Peshawar, Pakistan.

\section{Statistical Analysis}

Data on various morphological and biochemical traits were subjected to basic statistical analysis to measure the genetic variation in the collected landraces of $B$. napus L. according to Gomez and Gomez (1984). Cluster and principal component analyses were carried out on ten morphological and four biochemical traits for the years 2012 and 2013 separately using NTSYS-pc, version 2.1 (Rohlf, 2002) and STATISTICA-6 program as described by Sneath and Sokal (1973). Basic statistics of all accessions of B. napus L. used in the present study is shown in Tables 3 and 4 .

\section{Results}

Descriptive statistical analysis showed significant differences among the landraces for majority of the studied traits (Tables 3 and 4). During 2012 and 2013, among landraces of $B$. napus L., the maximum genetic variation was recorded for plant height [205.7 $\mathrm{cm}$ (ranging from 186.0 to 230.0 $\mathrm{cm}$ ) and $225.9 \mathrm{~cm}$ (ranging from 173.0 to $263.0 \mathrm{~cm}$ )], 
Genetic Diversity in Brassica Napus / Int. J. Agric. Biol., Vol. 20, No. 2, 2018

Table 1: Germplasm (including 68 accessions and two cultivars) of Brassica napus used in the present study

\begin{tabular}{|c|c|c|c|c|c|c|c|c|c|}
\hline Accession \# & Location of collection & $\begin{array}{l}\text { Plant } \\
\text { Type }\end{array}$ & Maturity & $\begin{array}{l}\text { Aphids (Resistant } \\
\text { /Susceptible) }\end{array}$ & Accession \# & $\begin{array}{l}\text { Location } \\
\text { collection }\end{array}$ & $\begin{array}{l}\text { f Plant } \\
\text { Type }\end{array}$ & Maturity & $\begin{array}{l}\text { Aphids (Resistant } \\
\text { /Susceptible) }\end{array}$ \\
\hline 24842 & Khanpur (KPP) & Erect & Medium & Resistant & 24876 & Sundas (NA) & Erect & Early & Susceptible \\
\hline 24843 & Okara (PP) & Erect & Medium & Susceptible & 24877 & Shakarghar (PP) & Erect & Early & Susceptible \\
\hline 24844 & Dara (KPP) & Erect & Medium & Susceptible & 24878 & Ghizer (NA) & Erect & Medium & Susceptible \\
\hline 24845 & Swabi (KPP) & Erect & Medium & Susceptible & 24879 & Mardan (KPP) & Erect & Medium & Susceptible \\
\hline 24846 & Rawalpindi (PP) & Erect & Medium & Resistant & 24880 & Attock (PP) & Erect & Medium & Susceptible \\
\hline 24847 & Tank (KPP) & Erect & Medium & Susceptible & 24881 & Khairabad (KPP) & Erect & Medium & Resistant \\
\hline 24848 & Islamabad (C) & Erect & Medium & Susceptible & 24882 & Mattani (KPP) & Erect & Early & Resistant \\
\hline 24849 & Haripur West (KPP) & Erect & Medium & Susceptible & 24884 & Bunner (KPP) & Erect & Early & Susceptible \\
\hline 24850 & Nowshera (KPP) & Erect & Medium & Resistant & 24885 & Takhtbhai (KPP) & Erect & Medium & Susceptible \\
\hline 24851 & Batgram (KPP) & Erect & Medium & Susceptible & 24886 & Pabbi (KPP) & Erect & Medium & Susceptible \\
\hline 24852 & Chirat (KPP) & Erect & Medium & Susceptible & 24887 & Taxila (PP) & Erect & Medium & Susceptible \\
\hline 24853 & Mianwali (PP) & Erect & Medium & Susceptible & 24888 & Sarghoda (PP) & Erect & Early & Susceptible \\
\hline 24854 & Bannu (KPP) & Erect & Early & Susceptible & 24889 & Murree (PP) & Erect & Medium & Susceptible \\
\hline 24855 & Pannian (KPP) & Bushy & Early & Resistant & 24890 & PindiBhatian (PP) & Erect & Medium & Susceptible \\
\hline 24856 & Mansehra(KPP) & Erect & Late & Susceptible & 24891 & Ghizer (NA) & Erect & Medium & Susceptible \\
\hline 24857 & Charsada (KPP) & Erect & Medium & Susceptible & 24892 & Swat (KPP) & Bushy & Medium & Resistant \\
\hline 24858 & Shiekhupura (PP) & Erect & Medium & Resistant & 24893 & Haripur (KPP) & Erect & Early & Susceptible \\
\hline 24859 & Batgram (KPP) & Erect & Late & Susceptible & 24894 & Sheikhan (KPP) & Erect & Early & Susceptible \\
\hline 24860 & Rahim Yar Khan (PP) & Erect & Medium & Susceptible & 24895 & Batgram (KPP) & Erect & Medium & Susceptible \\
\hline 24861 & Rsialpur (KPP) & Bushy & Medium & Resistant & 24896 & Balakot (KPP) & Erect & Medium & Susceptible \\
\hline 24862 & Chamkani (KPP) & Erect & Late & Susceptible & 24897 & Miandam (KPP) & Erect & Medium & Susceptible \\
\hline 24863 & Tarnul (PP) & Erect & Medium & Susceptible & 24898 & Batkhalla (KPP) & Erect & Medium & Resistant \\
\hline 24863 & Taxila (PP) & Erect & Early & Susceptible & 24899 & Shangla (KPP) & Erect & Late & Susceptible \\
\hline 24864 & Shabqadar (KPP) & Erect & Medium & Resistant & 24900 & Azakhail (KPP) & Erect & Medium & Susceptible \\
\hline 24865 & Khairabad (KPP) & Erect & Medium & Susceptible & 24901 & Abakhel (KPP) & Erect & Medium & Susceptible \\
\hline 24866 & Kurram Agency (FATA) & Erect & Late & Susceptible & 24902 & Shahbazkhel (KPP) & Erect & Medium & Susceptible \\
\hline 24867 & Mahandri (KPP) & Bushy & Medium & Resistant & 24903 & Peharkhel 01 (KPP) & Erect & Medium & Susceptible \\
\hline 24868 & Kohat (KPP) & Erect & Medium & Susceptible & 24904 & Rawat (PP) & Erect & Medium & Resistant \\
\hline 24869 & Faisalabad (PP) & Erect & Late & Susceptible & 24905 & Jaglot (NA) & Erect & Late & Susceptible \\
\hline 24870 & Miandam (KPP) & Erect & Medium & Susceptible & 24906 & Sultan abad (NA) & Bushy & Medium & Susceptible \\
\hline 24871 & Fateh Jang (PP) & Erect & Medium & Susceptible & 24907 & Havellain (KPP) & Erect & Medium & Susceptible \\
\hline 24872 & Swabi (KPP) & Erect & Medium & Susceptible & 24908 & Abbottabad (KPP) & Erect & Early & Susceptible \\
\hline 24873 & Peshawar (KPP) & Erect & Medium & Susceptible & 24909 & Dargai (KPP) & Erect & Medium & Resistant \\
\hline 24874 & Jhelum (PP) & Erect & Early & Susceptible & Shiralee & NARC, Islamabad & Erect & Medium & Resistant \\
\hline 24875 & Rawlakot (AJK) & Erect & Medium & Susceptible & Pakola & NARC, Islamabad & Erect & Medium & Resistant \\
\hline
\end{tabular}

KPP = Khyber Pakhtunkhwa Province, PP = Punjab Province, $\mathrm{C}=$ Capital, FATA $=$ Federally Administered Tribal Areas, AJK = Azad Jammu and Kashmir, NA = Northern Areas

Table 2: Classification of earliness, morphological and yield related traits in B. napus L. during 2012 and 2013

Trait designation Traits description

\section{Flowering stage}

Days to flower Initiation

Days to $50 \%$ flowering

Days to flower completion

Leaf petiole length $(\mathrm{cm})$

Leaf length $(\mathrm{cm})$

Leaf width $(\mathrm{cm})$

Leaves per plant

Plant height

Primary branches per plant

Siliqua per main inflorescence

Length of main inflorescence

D. Maturity stage

Days to maturity

Siliqua length (mm)

Siliqua width $(\mathrm{mm})$

Seeds per silique

Seed yield per plant

1000-seed weight (g)
Number of days from seed sowing to the appearance of first open flower

Days from seed sowing until 50\% of plants have the first flower in each accession

Number of days taken from date of sowing to the date at which about $95 \%$ population in an accession showed bloom.

Length from the stem to the lamina base including lobes of largest leaf

Length of largest leaf from the stem to the apex of leaf blade including petiole

Lamina width across the widest portion of the same leaf used for leaf length

Total number of developed leaves or leaf scars on the main stem

Plant height was measured in centimeters from the ground level to the tip of the plant with the help of a meter rod for each selected plant

Number of primary branches per plant was recorded from the ground level to the base of main raceme of each selected plant in each accession

Number of silique main inflorescence ${ }^{-1}$ was obtained by counting the total silique formed from the base to the tip of the main inflorescence

For this trait data were recorded on middle one inflorescence emerging from main shoot towards top

Days taken from seed sowing to the physiological maturity of the crop

Measured from the base to the tip of the silique

Measured at the thickest portion of the same silique used for SL

Counted as total number of seeds of same pod used for SL

Seed yield per plant was recorded by threshing all silique from the selected plants and weighing them on single plant basis using electronic balance in each accession Weight of 1000 dry seeds followed by days to flowering [120.8 days (ranging from 99.0 to 133.0 days) and 101.2 days (ranging from 70.0 to 131.0 days)] and days to maturity [166.8 days (ranging from 142.0 to 181.0 days) and 165.2 days (ranging from 158.0 to 179.8 days)], respectively. However, low variation was noticed for rest of the traits particularly 
seed oil quality traits. Generally, accessions varied for several traits of economic importance, but also showed dissimilar pattern of variation for various morphological and yield traits.

During 2012, cluster constructed for 70 genotypes (including two check cultivars i.e., Pakola and Shiralee) of $B$. napus $\mathrm{L}$. was further divided into nine main groups (Fig. 1). Each group was further subdivided into clusters. Group-I had three sub-clusters and comprised of 25 genotypes. The genotypes included in this group were early in maturity, and have long main raceme length, moderate plant height, long silique length and moderate oil and protein content. Group-II was subdivided into two clusters, and cluster one comprised of four genotypes, while cluster two had 14 genotypes. These genotypes were having moderate maturity and plant height, long silique length, more seeds per silique, bold seeds and moderate oil and protein contents (Table 8).

Group-III comprised of four clusters, and among them cluster one had two genotypes, cluster two had seven genotypes, and clusters three and four owned two and eight genotypes, respectively (Fig. 1). Features of the genotypes in this group were; tall plants, more branches, long main raceme length, more silique per plant, long silique length, more seeds per silique and seed yield, high oil and oleic acid content (Table 8). Group-IV and V contained one each cluster and four and three genotypes, respectively, and distinguishing traits of these genotypes were late maturity, more branches, silique per main raceme, seeds per silique, bold seeds, and more seed yield, while low glucosinolates, high erucic acid and oleic acid (Table 8). Groups VI, VII and IX had one each cluster and one genotype, while Group VIII had one cluster and two genotypes. The genotypes included in these groups were late in maturity, with dwarf plant height, low seed yield, and high protein and glucosinolate contents.

During 2013, the composition of cluster constructed for B. napus L. 70 genotypes including two check cultivars revealed seven main groups (Fig. 2). Group-I was further divided into four sub-clusters and among them cluster one has four genotypes, cluster two has two, three has six and cluster four has four genotypes and these genotypes were had early maturity, long raceme length, more seeds per silique, high glucosinolate content and moderate seed yield, oil and protein content (Table 9). Group-II has one cluster and five genotypes which were moderate for plant height, long main raceme length, moderate silique per main raceme, bold seeds, high glucosinolate and erucic contents, moderate oil and protein contents. Genotypes falling in group-III, were early maturing, tall, more branches, long siliques, more seeds per silique, high seed yield and protein (Table 9).Genotypes in group-IV were having more branches, long raceme length, bold seed, high oil and oleic acids, while low glucosinolate and linoleic acid. Group- $\mathrm{V}$ comprised of four sub-clusters, and six genotypes were placed in cluster one,

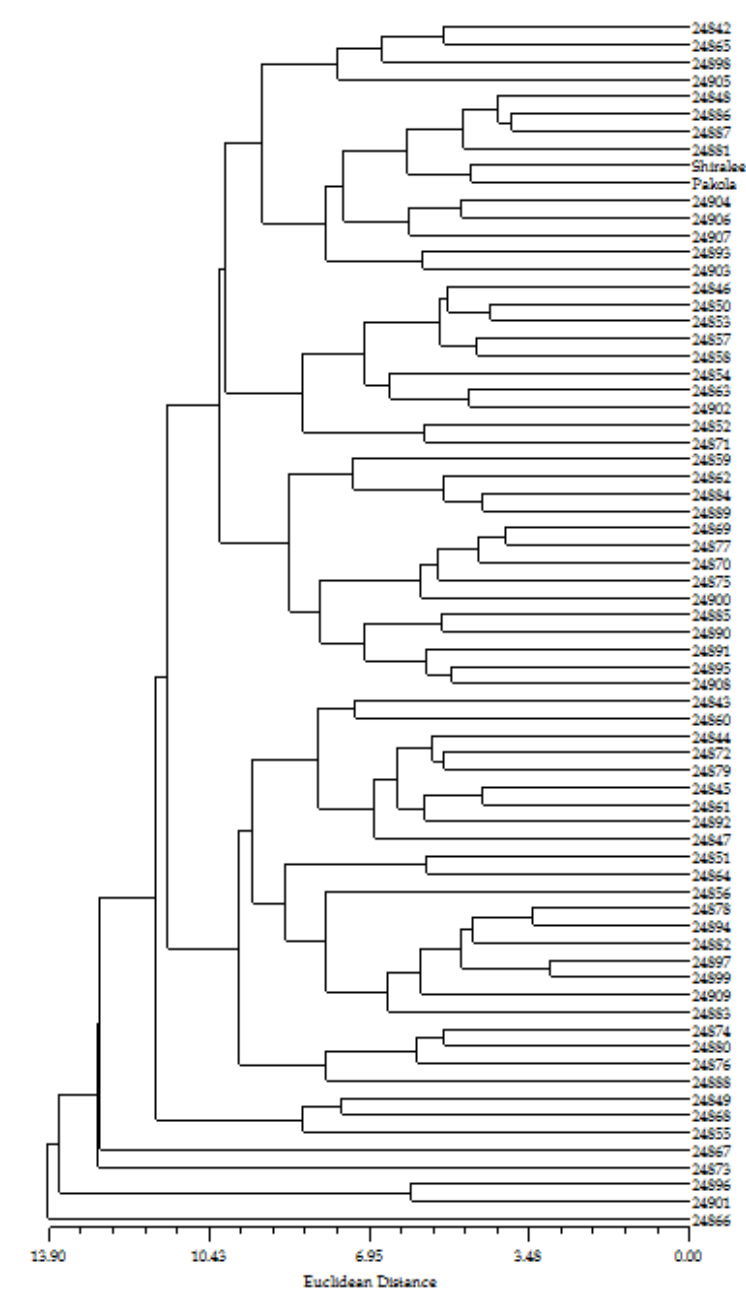

Fig. 1: Dendrogram presenting genetic relationship among 70 genotypes (including 68 indigenous landraces and two cultivars) of B. napus L. during 2012

cluster two and three each had four genotypes, while cluster four had three genotypes and distinguishing features were late maturity, tall plants, long main raceme length and silique length, more seeds per silique, high oil and oleic acid (Table 9). Group-VI was having four sub-clusters, and among them, he cluster one had four genotypes, cluster two had two genotypes, while clusters three and four had three each genotypes. Genotypes included in this group revealed long silique length, moderate seeds per silique and seed yield, high oil and oleic acid contents. Group-VII had four clusters, cluster one had one genotype, clusters two and three had four each genotypes, and cluster four had two genotypes with late maturity, high erucic acid and low oleic acid content.

Principal component analysis (PCA) is a data analysis tool usually used to reduce the dimensionality (number of variables) of a large number of inter-related variables, while retaining as much of the information (variation) as possible. 
Genetic Diversity in Brassica Napus / Int. J. Agric. Biol., Vol. 20, No. 2, 2018

Table 3: Means and variances for earliness, morphological, yield and biochemical traits in B. napus L. during 2012

\begin{tabular}{|c|c|c|c|c|c|c|}
\hline Traits & Mean & Minimum & Maximum & Variance & $\mathrm{SD}$ & $\mathrm{CV}(\%)$ \\
\hline Days to flower initiation & 65.3 & 49.0 & 89.0 & 10.0 & 15.4 & 17.4 \\
\hline Days to $50 \%$ flowering & 97.4 & 65.0 & 112.0 & 8.3 & 8.5 & 14.5 \\
\hline Days to flower completion & 120.8 & 99.0 & 133.0 & 7.9 & 6.6 & 17.2 \\
\hline Days to maturity & 166.8 & 142.0 & 181.0 & 8.3 & 5.0 & 3.1 \\
\hline Leaf petiole length & 15.0 & 3.9 & 23.2 & 4.9 & 32.6 & 29.7 \\
\hline Leaf length & 25.2 & 13.9 & 34.0 & 3.8 & 15.3 & 23.5 \\
\hline Leaf width & 10.5 & 4.3 & 16.0 & 2.5 & 23.6 & 39.6 \\
\hline Leaf length/width ratio & 2.5 & 1.2 & 4.5 & 0.6 & 25.3 & 24.2 \\
\hline Leaves/plant & 20.5 & 14.0 & 28.0 & 3.0 & 14.8 & 13.2 \\
\hline Plant height & 205.7 & 186.0 & 230.0 & 11.1 & 5.4 & 6.5 \\
\hline Primary branches/plant & 11.4 & 8.0 & 14.0 & 1.7 & 15.0 & 23.2 \\
\hline Main raceme length & 65.1 & 39.0 & 81.0 & 11.2 & 17.1 & 17.4 \\
\hline Silique/main raceme & 58.1 & 29.0 & 83.0 & 12.0 & 20.6 & 21.3 \\
\hline Silique length & 7.5 & 6.8 & 8.5 & 0.4 & 5.8 & 16.3 \\
\hline Silique width & 0.6 & 0.2 & 0.9 & 0.2 & 29.1 & 14.4 \\
\hline Siliqua length/width ratio & 14.6 & 7.6 & 37.0 & 5.2 & 35.9 & 19.3 \\
\hline Seeds/silique & 26.2 & 20.0 & 32.0 & 3.4 & 13.1 & 23.2 \\
\hline Seed yield/plant & 45.7 & 22.5 & 103.7 & 14.9 & 32.7 & 30.4 \\
\hline 1000 -seed weight & 3.5 & 3.2 & 4.1 & 0.2 & 5.3 & 26.8 \\
\hline Oil content & 45.5 & 29.8 & 51.9 & 4.0 & 8.8 & 6.1 \\
\hline Protein content & 25.6 & 21.2 & 30.3 & 2.4 & 9.2 & 7.3 \\
\hline Glucosinolates & 100.8 & 12.7 & 163.6 & 27.1 & 26.9 & 22.3 \\
\hline Oleic acid & 42.8 & 26.8 & 56.3 & 7.5 & 17.4 & 15.7 \\
\hline Linoleic acid & 11.4 & 9.5 & 15.2 & 1.5 & 12.7 & 14.3 \\
\hline Erucic acid & 53.8 & 21.6 & 60.9 & 8.5 & 15.7 & 16.3 \\
\hline
\end{tabular}

Table 4: Means and variances for earliness, morphological, yield and biochemical traits in B. napus L. during 2013

\begin{tabular}{|c|c|c|c|c|c|c|}
\hline Traits & Mean & Minimum & Maximum & Variance & SD & $\mathrm{CV}(\%)$ \\
\hline Days to flower initiation & 68.6 & 47.0 & 93.0 & 164.3 & 12.8 & 18.7 \\
\hline Days to $50 \%$ flowering & 86.4 & 59.0 & 120.0 & 186.2 & 13.6 & 15.8 \\
\hline Days to flower completion & 101.2 & 70.0 & 131.0 & 230.8 & 15.2 & 15.0 \\
\hline Days to maturity & 165.2 & 158.0 & 179.8 & 18.0 & 4.2 & 2.6 \\
\hline Leaf petiole length & 17.9 & 6.9 & 33.3 & 35.0 & 5.9 & 33.0 \\
\hline Leaf length & 41.9 & 13.6 & 61.5 & 109.3 & 10.5 & 25.0 \\
\hline Leaf width & 14.8 & 6.7 & 61.2 & 39.2 & 6.3 & 42.1 \\
\hline Leaf length per width ratio & 2.9 & 0.7 & 4.6 & 0.4 & 0.7 & 22.3 \\
\hline Leaves per plant & 20.0 & 12.0 & 28.0 & 10.7 & 3.3 & 16.4 \\
\hline Plant height & 225.9 & 173.0 & 263.0 & 343.8 & 18.5 & 8.2 \\
\hline Primary branches per plant & 11.7 & 6.0 & 18.0 & 6.1 & 2.5 & 21.1 \\
\hline Main raceme length & 76.3 & 46.0 & 96.0 & 157.1 & 12.5 & 16.4 \\
\hline Siliqua per main raceme & 73.8 & 28.0 & 102.0 & 195.1 & 14.0 & 18.9 \\
\hline Siliqua length & 6.2 & 2.7 & 9.2 & 1.1 & 1.1 & 17.2 \\
\hline Siliqua width & 0.5 & 0.3 & 0.6 & 0.0 & 0.1 & 11.9 \\
\hline Siliqua length per width ratio & 13.4 & 8.9 & 18.8 & 4.3 & 2.1 & 15.4 \\
\hline Seeds per siliqua & 25.1 & 4.6 & 34.0 & 26.3 & 5.1 & 20.4 \\
\hline Seed yield per plant & 50.7 & 25.0 & 108.7 & 277.4 & 16.7 & 32.8 \\
\hline 1000-seed weight & 3.2 & 1.8 & 5.1 & 0.8 & 0.9 & 28.2 \\
\hline Oil content & 46.4 & 39.9 & 53.3 & 6.3 & 2.5 & 5.4 \\
\hline Protein content & 25.0 & 19.2 & 31.9 & 4.4 & 2.1 & 8.4 \\
\hline Glucosinolates & 96.9 & 49.2 & 152.0 & 564.6 & 23.8 & 24.5 \\
\hline Oleic acid & 46.6 & 29.0 & 60.1 & 48.2 & 6.9 & 14.9 \\
\hline Linoleic acid & 9.3 & 6.7 & 14.8 & 2.3 & 1.5 & 16.3 \\
\hline Erucic acid & 49.3 & 15.3 & 74.2 & 93.7 & 9.7 & 19.6 \\
\hline
\end{tabular}

Moreover, PCA calculates an unrelated set of variables (factors or principal components) and gives supplementary information on usefulness of characters for definition of groups. When the PCA is run on correlations, one rule-ofthumb is to retain those factors whose eigenvalues are greater than one.

Principal component analysis constructed based on various quantitative traits in $B$. napus L. produced very informative outcome of the studied genotypes (Fig. 3 and 4). The coefficients defining five principal components for B. napus L. grown during 2012 are given in Table 5. These coefficients were scaled to observe correlation between observed variables and derived components. The first principal component had $14.13 \%$ of the total variation in morphological and biochemical characters. 


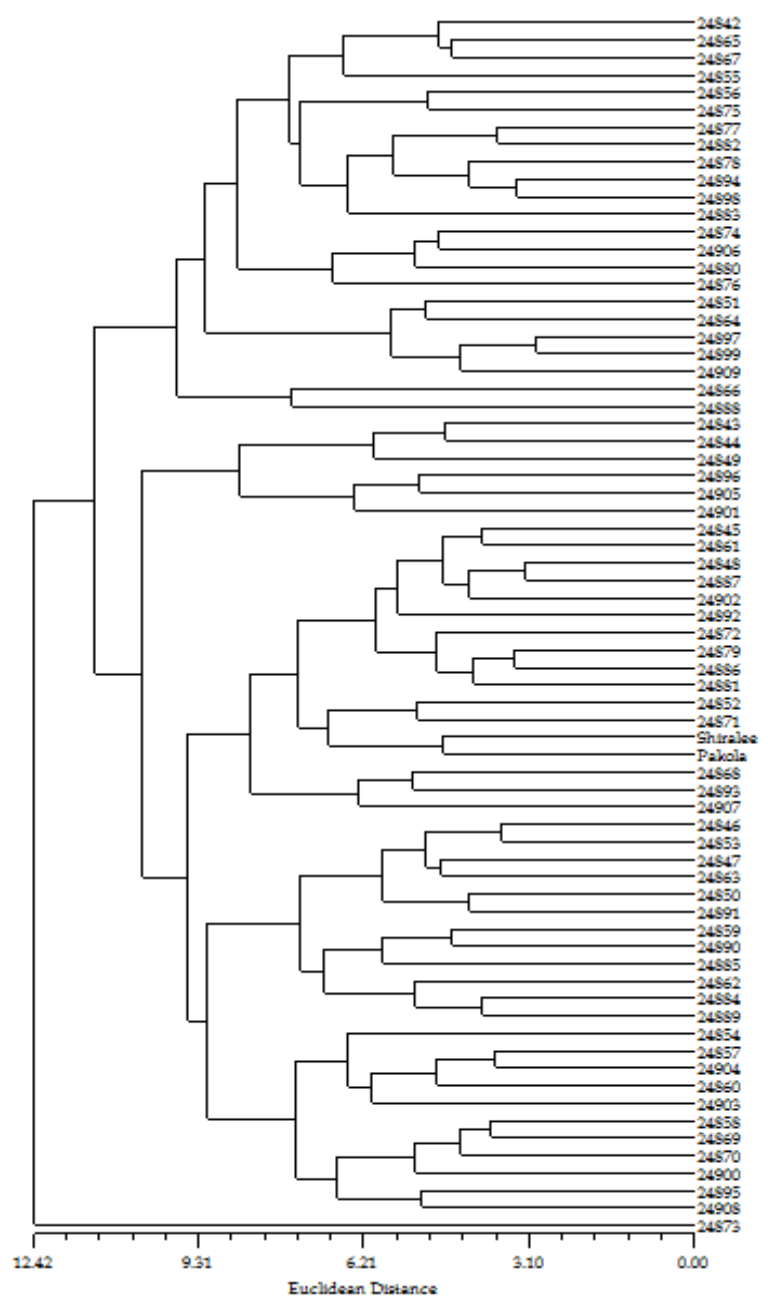

Fig. 2: Dendrogram presenting genetic relationship among 70 genotypes (including 68 indigenous landraces and two cultivars) of B. napus L. during 2013

In PC1, demonstrated mainly the variations in linoleic acid (0.40), protein (0.39) and glucosinolates (0.37) contributed positively. Contributions of leaf length/leaf width ratio $(-0.01)$, leaf petiole length $(-0.06)$ and plant height $(-0.08)$ were negative (Table5).

The PC2 accounted for an additional13.1\%, having $50 \%$ flowering (0.37). Flower completion (0.37) and silique length (0.32), while primary branches $(-0.05)$, oil content (-0.06) and oleic acid (-0.17) contributed negatively (Table 5). The variation in PC3 was mainly attributed to $10.55 \%$ of the total variation and comprised of silique length $(0.36)$, silique length per width ratio (0.33) and seeds per silique (0.33), whereas glucosinolates (-0.02), oil content (-0.03) and flower initiation (-0.04) had negative contribution (Table 5).

The fourth principal component accounted for $9.85 \%$ of divergence, having flower initiation (0.44), $50 \%$ flowering (0.39) and days to flower completion (0.32) but inversely with linoleic acid (-0.01), silique width (-0.06)

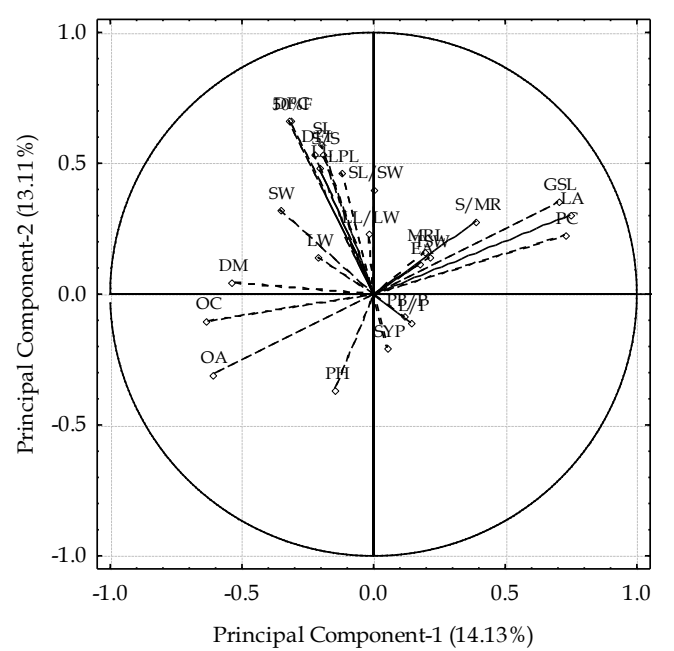

Fig. 3: Contribution of quantitative and qualitative traits in $1^{\text {st }}$ and $2^{\text {nd }}$ PCs in 70 genotypes (including 68 indigenous landraces and two cultivars) of B. napus L. during 2012

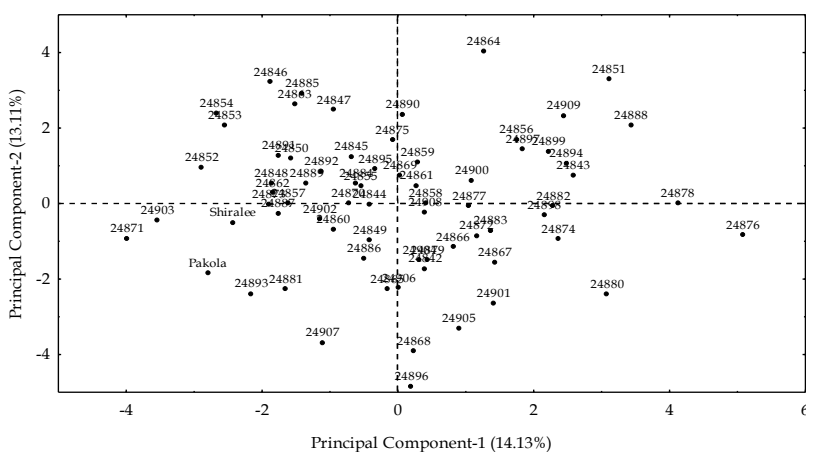

Fig. 4: Scatter diagram for $1^{\text {st }}$ and $2^{\text {nd }} P C$ for 25 earliness, morphological, yield and biochemical traits in 70 genotypes (including 68 indigenous landraces and two cultivars) of B. napus L. during 2012

and silique main per raceme $(-0.08)$ (Table 5). The PC5 accounted for an additional $8.25 \%$ of the total variation having glucosinolates $(0.31)$, oil content $(0.28)$ and erucic acid (0.23). On the other hand, seed per silique (-0.01), plant height (-0.02) and 50\% flowering (-0.03) had negative values (Table 5).

The coefficients defining five principal components for $B$. napus L. genotypes grown during second growing season 2013 are given in Table 6 (Fig. 5 and 6). These coefficients were scaled, to observe correlations between observed variables and derived components. The PC1 had $22.54 \%$ of the total variation in morphological and biochemical characters.

In $\mathrm{PC} 1$, flower completion (0.32), 50\% flowering (0.28) and plant height $(0.27)$ contributed positively, while protein content $(-0.01)$, leaf length per leaf width ratio (-0.04) and 1000-seed weight (-0.05) contributed negatively (Table 6). 
Table 5: Principal components analysis for earliness, morphological, yield and biochemical traits in B. napus L. during 2012

\begin{tabular}{|c|c|c|c|c|c|}
\hline & PC1 & $\mathrm{PC} 2$ & PC3 & PC4 & PC5 \\
\hline Eigenvalues & 3.53 & 3.28 & 2.64 & 2.46 & 2.06 \\
\hline Cumulative eigenvalues & 3.53 & 6.81 & 9.45 & 11.91 & 13.97 \\
\hline Variance $\%$ & 14.13 & 13.11 & 10.55 & 9.85 & 8.25 \\
\hline Cumulative variance & 14.13 & 27.25 & 37.80 & 47.65 & 55.90 \\
\hline Traits & \multicolumn{5}{|c|}{ Eigenvectors } \\
\hline Days to flower initiation & -0.12 & 0.30 & -0.04 & 0.44 & 0.09 \\
\hline Days to $50 \%$ flowering & -0.17 & 0.37 & 0.02 & 0.39 & -0.03 \\
\hline Days to flower completion & -0.17 & 0.37 & 0.03 & 0.32 & -0.07 \\
\hline Days to maturity & -0.29 & 0.03 & 0.01 & -0.03 & 0.14 \\
\hline Leaf petiole length & -0.06 & 0.26 & -0.31 & -0.21 & -0.15 \\
\hline Leaf length & -0.11 & 0.27 & -0.41 & -0.20 & -0.12 \\
\hline Leaf width & -0.11 & 0.08 & 0.03 & -0.24 & -0.31 \\
\hline Leaf length per width ratio & -0.01 & 0.13 & -0.39 & 0.00 & 0.12 \\
\hline Leaves per plant & 0.08 & -0.06 & 0.29 & -0.05 & -0.17 \\
\hline Plant height & -0.08 & -0.20 & 0.06 & -0.02 & -0.02 \\
\hline Primary branches per plant & 0.06 & -0.05 & 0.02 & 0.19 & -0.29 \\
\hline Main raceme length & 0.10 & 0.09 & -0.20 & -0.09 & -0.36 \\
\hline Siliqua per main raceme & 0.21 & 0.16 & -0.10 & -0.08 & -0.38 \\
\hline Siliqua length & -0.11 & 0.32 & 0.36 & -0.26 & 0.02 \\
\hline Siliqua width & -0.19 & 0.18 & 0.11 & -0.06 & 0.17 \\
\hline Siliqua length per width ratio & 0.00 & 0.22 & 0.33 & -0.25 & -0.10 \\
\hline Seeds per siliqua & -0.10 & 0.30 & 0.33 & -0.18 & -0.01 \\
\hline Seed yield per plant & 0.03 & -0.11 & 0.19 & 0.31 & -0.06 \\
\hline 1000 -seed weight & 0.11 & 0.08 & -0.11 & 0.12 & 0.14 \\
\hline Oil content & -0.34 & -0.06 & -0.03 & -0.18 & 0.28 \\
\hline Protein content & 0.39 & 0.13 & 0.11 & 0.13 & -0.12 \\
\hline Glucosinolates & 0.37 & 0.20 & 0.01 & -0.04 & 0.31 \\
\hline Oleic acid & -0.33 & -0.17 & -0.02 & 0.12 & -0.33 \\
\hline Linoleic acid & 0.40 & 0.17 & 0.03 & -0.01 & 0.10 \\
\hline Erucic acid & 0.09 & 0.06 & -0.15 & -0.16 & 0.23 \\
\hline
\end{tabular}

Second principal component contributed variation of $16.69 \%$, having flower initiation (0.34), $50 \%$ flowering (0.29), protein content $(0.29)$, while primary branches $(-0.07)$, leaf petiole length $(-0.14)$ and siliqua length per width ratio $(-0.16)$ had contributed negatively. The PC3resulted with $7.91 \%$ of the total variation and comprised of glucosinolates content (0.42), linoleic acid (0.31) and silique width (0.28), whereas seed yield per plant (-0.06), flower completion $(-0.07)$ and $50 \%$ flowering $(-0.10)$ had negative contribution (Table 6).

The PC4 accounted for $6.54 \%$ of divergence, having leaf width (0.39), main raceme length (0.37) and silique main per raceme (0.35) but inversely with linoleic acid (-0.02), leaf length $(-0.10)$ and flower completion (-0.11). The total contribution of fifth component was $6.11 \%$ of the total variation having silique length per width ratio (0.34), silique length $(0.33)$ and seeds per silique $(0.28)$. On the other hand, the linolenic acid $(-0.02)$, protein content $(-0.08)$ and seed yield per plant $(-0.08)$ had negative values (Table 6).

Principal component analysis based on B. napus L. genotypes showed different grouping pattern, indirectly supporting cluster analysis (Fig. 4 and 6). The separation based on PC1 and PC2 revealed that the genotypes were distributed in all the directions, which clearly identified the diversity of the experimental materials (Fig. 4 and 6).
Table 6: Principal components analysis for earliness, morphological, yield and biochemical traits in B. napus L. during 2013

\begin{tabular}{llllll}
\hline & PC1 & PC2 & PC3 & PC4 & PC5 \\
\hline Eigenvalues & 5.63 & 4.17 & 1.98 & 1.63 & 1.53 \\
Cumulative eigenvalues & 5.63 & 9.81 & 11.78 & 13.42 & 14.95 \\
Variance \% & 22.54 & 16.69 & 7.91 & 6.54 & 6.11 \\
Cumulative variance & 22.54 & 39.23 & 47.14 & 53.67 & 59.79 \\
Traits & Eigenvectors & & & \\
Days to flower initiation & 0.21 & 0.34 & -0.14 & -0.14 & 0.05 \\
Days to 50\% flowering & 0.28 & 0.29 & -0.10 & -0.14 & 0.06 \\
Days to flower completion & 0.32 & 0.25 & -0.07 & -0.11 & 0.05 \\
Days to maturity & 0.28 & 0.21 & 0.15 & 0.13 & -0.10 \\
Leaf petiole length & 0.25 & -0.14 & 0.19 & -0.14 & -0.27 \\
Leaf length & 0.19 & -0.10 & 0.20 & -0.10 & -0.33 \\
Leaf width & 0.15 & 0.11 & 0.06 & 0.39 & 0.25 \\
Leaf length per width ratio & -0.04 & -0.22 & 0.01 & -0.46 & -0.48 \\
Leaves per plant & 0.24 & 0.11 & -0.19 & -0.11 & 0.05 \\
Plant height & 0.27 & 0.12 & 0.08 & 0.18 & -0.14 \\
Primary branches per plant & 0.14 & -0.07 & -0.21 & -0.13 & 0.03 \\
Main raceme length & 0.12 & -0.18 & 0.22 & 0.37 & -0.21 \\
Siliqua per main raceme & 0.17 & -0.22 & 0.20 & 0.35 & -0.09 \\
Siliqua length & 0.24 & -0.20 & 0.26 & -0.18 & 0.33 \\
Siliqua width & 0.21 & -0.12 & 0.28 & -0.16 & 0.13 \\
Siliqua length per width ratio & 0.14 & -0.16 & 0.06 & -0.11 & 0.34 \\
Seeds per siliqua & 0.22 & -0.24 & 0.25 & -0.16 & 0.28 \\
Seed yield per plant & 0.18 & 0.20 & -0.06 & 0.02 & -0.08 \\
1000-seed weight & -0.05 & 0.09 & 0.17 & 0.26 & -0.12 \\
Oil content & -0.04 & -0.30 & -0.14 & 0.02 & 0.19 \\
Protein content & -0.01 & 0.29 & 0.29 & -0.16 & -0.08 \\
Glucosinolates & -0.22 & 0.20 & 0.42 & -0.12 & 0.06 \\
Oleic acid & 0.27 & -0.17 & -0.27 & 0.10 & -0.14 \\
Linoleic acid & -0.15 & 0.26 & 0.31 & -0.02 & -0.02 \\
Erucic acid & -0.19 & 0.03 & 0.11 & -0.15 & 0.15 \\
\hline & & & & & \\
& & & & \\
& & & & &
\end{tabular}

In the first and second principal components, the genotypes 24864, 24851, 24888, 24876, 24878, 24880, 24896, 24907 and 24871 were the most variable ones among the studied genotypes. In the first and third principal components, genotypes 24866, 24876, 24878, 24901, 24871 and 24903 showed greater genetic diversity. The determined variability can be used in the in the future breeding programs to preserve the precious germplasm from genetic erosion. Promising genotypes (24847, 24866, 24850, 24877 and 24843) were identified with potential genes of interest to improve earliness, yield components and oil content (Table 7).

Overall, the results revealed that significant differences were observed among the 70 landraces with considerable level of genetic variability for majority of the traits. Major variability producing traits were plant height and time to maturity, while adequate variations were recorded for flower completion, 50\% flower initiation, glucosinolate content, main raceme length and silique per main raceme.

During 2012, cluster analysis divided the total 70 landraces into nine main groups and contributions of five principal components. In 2013, cluster for above genotypes was categorized into seven main groups and the contributions of five principal components. Accessions used in the present study produced a reasonable level of variations for various traits. 


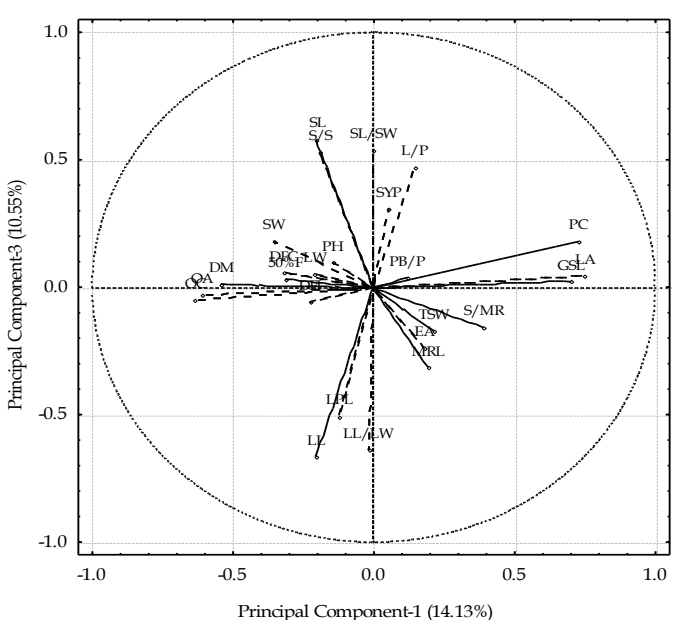

Fig. 5: Contribution of quantitative and qualitative traits in $1^{\text {st }}$ and $2^{\text {nd }}$ PCs in 70 genotypes (including 68 indigenous landraces and two cultivars) of B. napus L. during 2013

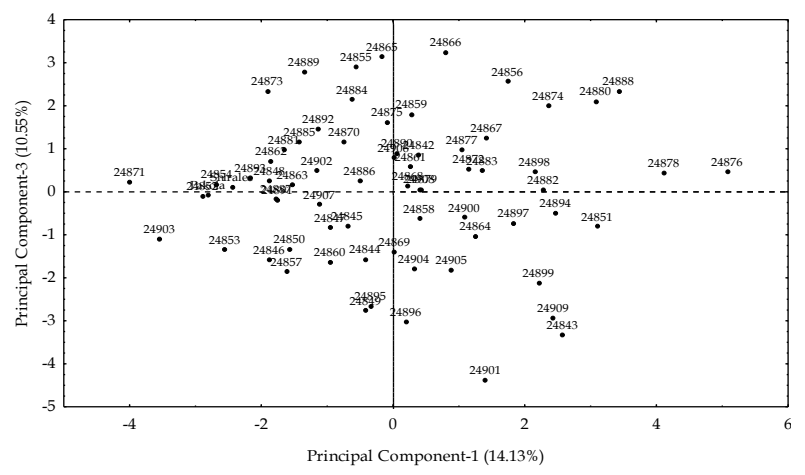

Fig. 6: Scatter diagram for $1^{\text {st }}$ and $2^{\text {nd }} \mathrm{PC}$ for earliness, morphological, yield and biochemical traits in 70 genotypes (including 68 indigenous landraces and two cultivars) of B. napus L. during 2013

\section{Discussion}

Morphological characterization is the first step in description and classification of genetic resources (Arslanoglu et al., 2011). Landraces are open pollinated populations whereas commercial cultivars are hybrids selected for uniformity and production synchrony, and been improved using only primitive mass selection. In order to choose the best genotypes for the inclusion in breeding programs, the landraces with significant genetic variations should be selected. However, for characters related to crop uniformity in brassica, the commercial cultivars and hybrids did better than landraces of brassica (Padilla et al., 2007; Ali et al., 2015). For centuries, farmers through mass selection have improved populations/landraces; however, their cultivation is reducing than entire crop area. Compared with commercial hybrids, the local populations of brassica are less productive and lack uniformity and field durability however, these brassica populations are valuable genetic resources and should be released as commercial cultivars after evaluation, and to be conserved in the gene bank for future breeding programs (Balkaya et al., 2005).

In present studies, significant variations were observed in indigenous landraces of $B$. napus $\mathrm{L}$. for plant height, days to flower completion and maturity followed by yield related traits and oil quality parameters. Variations for seed yield followed by plant height, glucosinolates content, main raceme length, and silique per main raceme were observed in various populations of $B$. carinata $\mathrm{L}$. (Zada et al., 2013). Similarly, some past studies revealed significant variation among various landraces of $B$. campestris L. (Yousaf et al., 2011) and S. indicum L. (Akbar et al., 2011) for seed yield and oil quality traits. The 509 B. napus L. inbred lines genotyped with 89 genomespecific SSR primer combinations, and principal coordinate analysis and software STRUCTURE revealed that genetic diversity of winter oilseed rape was lower than the diversity found in other germplasm types (Bus et al., 2011).

During growing seasons of 2012 and 2013, cluster constructed for B. napus L. 70 genotypes revealed nine and seven main major groups, respectively. These groups further sub-divided in different sub-clusters/groups and showed ample genetic variability through different traits i.e., plant height, main raceme length, silique per main raceme, seed size, oil, protein, glucosinolate and erucic acid content. In accessions of $B$. juncea L., scattered plot and tree diagrams demonstrated sufficient diversity for various morphological and biochemical traits and some extent of association was reported between different clusters (Ali et al., 2015).A set of 96 B. napus L. genotypes was characterized using SSR markers, and allelic information from 30 SSR primer combinations amplifying 220 alleles at 51 polymorphic loci and provided unique genetic fingerprints for all genotypes (Hasan et al., 2006).

In past findings, maximum genetic variation was observed in various genotypes of Indian mustard (B. juncea L.) for morphological, seed yield and oil quality traits (Rabbani et al., 1998a). From hierarchical cluster analysis, it was authenticated that genotypes collected from the same origin were not necessarily falling in the same cluster and had low diversity; rather the cluster analysis was more influenced by morphological traits than accession origin. Present findings also revealed that geographic origin of the B. napus accessions had no significant effect on varied grouping of the genotypes. Therefore, cluster is mostly made on traits basis and not based on origin in various Brassica populations (Gupta and Pratap, 2007; Hu et al., 2007; Rabbani et al., 1998b; Dhillon et al., 1999). However, it is also not necessary that the accessions/genotypes grouping always made because of their morphological traits, though some researchers were inconsistent with this opinion. Dias et al. (1993) grouped populations of Portuguese cabbage (B. oleraceaacephala) and Galega kale (B. oleracea var. acephala cv. Galega) based on their geographical origin and morphological differences. 
Table 7: Main characteristics of the 70 genotypes (including 68 indigenous landraces and two cultivars) of $B$. napus L. belonging to different clusters during 2012 and 2013

\begin{tabular}{lll}
\hline Trait of interest & Range & Accessions identified \\
\hline Days to maturity & $<160$ & $24876,27877,24882,24894,24908,24874,24854,24869$ and 24888 \\
Primary branches & $\geq 15$ & $24847,24849,24859,24872,24879,24878,24891,24848,24860,24865$ and 24900 \\
Main raceme length & $\geq 90$ & $24851,24863,24872,24878,24880,24885,24905,24906$ and Shiralee \\
Silique per main raceme & $\geq 90$ & $24843,24860,24909,24895,24844,24877,24884,24898$ and Pakola \\
Silique length & $\geq 7$ & $24847,24848,24892,24890,24888,24877,24874,24873,24870$ and Pakola \\
Seed per silique & $\geq 28$ & $24844,24845,24851,24854,24855,24856,24859,24885,24888$ and 24892 \\
Seed yield per plant & $\geq 80$ & $24866,24868,24882,24889,24896,24883,24880,24870$ and 24859 \\
1000-ssed weight & $\geq 4$ & $24843,24846,24849,24850,24864,24868,24869,24876,24877,24891,24898$ and Pakola \\
Oil content & $\geq 50$ & $24850,24852,24857,24871,24893,24882,24897$ and Shiralee \\
Protein content & $\geq 27$ & $24843,24851,24874,24880,24884,24888,24908$ and 24872 \\
Oleic Acid & $\geq 50$ & $24844,24849,24854,24861,24868,24870,24881,24890,24891,24907,24908$, Pakola and Shiralee \\
\hline
\end{tabular}

Table 8: Mean values and standard deviation (SD) of six clusters based on earliness, morphological, yield and biochemical traits in B. napus L. during 2012

\begin{tabular}{|c|c|c|c|c|c|c|c|c|c|c|c|c|}
\hline \multirow[t]{2}{*}{ Traits } & \multicolumn{2}{|c|}{ Group 1} & \multicolumn{2}{|c|}{ Group 2} & \multicolumn{2}{|c|}{ Group 3} & \multicolumn{2}{|c|}{ Group 4} & \multicolumn{2}{|c|}{ Group 5} & \multicolumn{2}{|c|}{ Group 6} \\
\hline & Mean & SD & Mean & SD & Mean & SD & Mean & $\mathrm{SD}$ & Mean & SD & Mean & $\mathrm{SD}$ \\
\hline Days to flower initiation & 66.84 & 10.29 & 63.21 & 8.09 & 83.00 & 16.09 & 82.00 & 19.40 & 82.00 & 17.37 & 67.60 & 12.70 \\
\hline Days to $50 \%$ flowering & 96.60 & 6.54 & 97.93 & 5.14 & 111.00 & 7.91 & 104.00 & 8.62 & 104.00 & 8.80 & 99.00 & 8.40 \\
\hline Days to flower completion & 119.72 & 8.22 & 120.86 & 5.83 & 133.00 & 5.09 & 127.00 & 5.00 & 127.00 & 3.88 & 123.20 & 4.60 \\
\hline Days to maturity & 166.24 & 9.04 & 168.93 & 6.16 & 181.00 & 4.16 & 177.00 & 6.43 & 177.00 & 4.35 & 170.80 & 1.64 \\
\hline Leaf petiole length & 15.65 & 5.62 & 15.11 & 4.66 & 23.00 & 46.44 & 17.00 & 29.55 & 14.90 & 25.44 & 12.82 & 4.25 \\
\hline Leaf length & 25.88 & 3.62 & 24.94 & 3.35 & 32.10 & 17.92 & 29.90 & 18.34 & 29.90 & 20.48 & 23.64 & 2.53 \\
\hline Leaf width & 10.09 & 1.99 & 10.31 & 1.98 & 14.00 & 25.48 & 12.80 & 26.06 & 8.80 & 4.92 & 11.70 & 4.64 \\
\hline Leaf length per width ratio & 2.65 & 0.57 & 2.51 & 0.58 & 3.81 & 25.66 & 2.20 & 2.71 & 2.20 & 13.23 & 2.29 & 0.85 \\
\hline Leaves per plant & 19.92 & 2.75 & 21.50 & 3.01 & 28.00 & 16.41 & 21.00 & 3.67 & 21.90 & 4.74 & 18.20 & 4.60 \\
\hline Plant height & 205.12 & 11.84 & 205.21 & 8.36 & 216.00 & 4.92 & 213.00 & 13.48 & 214.00 & 207.84 & 198.60 & 15.60 \\
\hline Primary branches per plant & 11.08 & 1.53 & 11.71 & 1.68 & 14.00 & 16.17 & 17.00 & 4.68 & 15.00 & 3.83 & 11.80 & 2.68 \\
\hline Main raceme length & 65.16 & 8.23 & 58.21 & 15.06 & 80.00 & 13.73 & 58.00 & 1.75 & 62.00 & 4.48 & 63.80 & 17.38 \\
\hline Siliqua per main raceme & 56.64 & 10.64 & 58.29 & 14.69 & 83.00 & 22.99 & 87.50 & 2.86 & 74.40 & 2.11 & 53.80 & 6.76 \\
\hline Siliqua length & 7.50 & 0.46 & 7.40 & 0.38 & 8.00 & 5.94 & 8.40 & 15.75 & 7.60 & 35.25 & 7.56 & 0.26 \\
\hline Siliqua width & 0.54 & 0.17 & 0.63 & 0.16 & 0.90 & 0.72 & 23.67 & 0.28 & 0.23 & 31.48 & 0.48 & 0.08 \\
\hline Siliqua length per width ratio & 15.65 & 6.10 & 12.85 & 4.82 & 26.67 & 38.98 & 29.00 & 13.68 & 29.00 & 5.52 & 16.06 & 2.29 \\
\hline Seeds per siliqua & 25.68 & 33.44 & 50.59 & 20.92 & 30.00 & 11.39 & 33.40 & 1.19 & 35.40 & 3.31 & 26.60 & 4.10 \\
\hline Seed yield per plant & 40.23 & 10.26 & 43.51 & 0.17 & 75.80 & 28.55 & 73.50 & 2.94 & 79.0 & 8.57 & 49.88 & 23.15 \\
\hline 1000-seed weight & 3.49 & 0.17 & 4.16 & 3.45 & 3.90 & 4.29 & 4.30 & 2.39 & 4.10 & 3.70 & 3.34 & 0.15 \\
\hline Oil content & 44.99 & 4.71 & 46.34 & 2.71 & 46.40 & 9.23 & 41.40 & 1.46 & 45.80 & 4.64 & 46.90 & 3.91 \\
\hline Protein content & 25.86 & 1.97 & 27.79 & 27.12 & 23.20 & 20.87 & 27.90 & 6.47 & 31.90 & 19.24 & 24.12 & 1.73 \\
\hline Glucosinolates & 96.84 & 29.02 & 69.17 & 6.84 & 56.30 & 11.74 & 54.50 & 3.83 & 54.50 & 10.60 & 97.10 & 25.45 \\
\hline Oleic acid & 43.28 & 7.42 & 41.84 & 1.66 & 51.90 & 8.09 & 47.80 & 10.84 & 51.80 & 12.33 & 40.72 & 7.60 \\
\hline Linoleic acid & 11.33 & 1.42 & 14.74 & 7.30 & 20.90 & 18.52 & 14.20 & 21.34 & 19.10 & 24.59 & 11.02 & 1.14 \\
\hline Erucic acid & 52.68 & 9.83 & 63.21 & 8.09 & 83.00 & 16.09 & 82.00 & 19.40 & 82.00 & 17.37 & 57.04 & 2.64 \\
\hline
\end{tabular}

There were certain relationships between geographical origin of germplasm collections of $B$. rapa subsp. rapa L. from northwestern Spain and the groups formed on basis of origin (Padilla et al., 2005). Similarly, Cartea et al. (2003) reported that landraces of $B$. oleracea have stronger relation by geographical origin rather than with morphological differences.

Grouping of some of the genotypes based on various ecological regions exhibited the association between morphological characters and geographical origin, indicated regional similarities in selection criterion, easy exchange of germplasm between neighboring regions and perhaps identical ancestors within these regions. Similarly, Abideen et al. (2013) and Rabbani et al. (1998a) findings revealed that cluster/grouping of B. napus L. and B. juncea L. genotypes was always made on traits basis, and which verified and strengthen the present phenomenon. Similarly, Rodriguez et al. (2005) also did classification based on characters and not based on their origin in 36 populations of B. napusL. var. pabularia crop. Balkaya et al. (2005) also concluded that there was no relationship between the morphological characters and geographical origin of the white head cabbage ( $B$. oleracea L.) genetic resources from Turkey. They reported that clustering of the different genotypes was based on their morphological values of hidden characters. Present results were further supported by the past findings about genetic diversity in B. campestris L., and B. napus L. (Chauhan et al., 2008). Amurrio et al. (1995) using Iberian pea landraces based on quantitative and qualitative characters, concluded that cluster groups were not related to the geographical origin of pea accessions. 
Table 9: Mean values and standard deviation (SD) of six clusters based on earliness, morphological, yield and biochemical traits in B. napus L. during 2013

\begin{tabular}{|c|c|c|c|c|c|c|c|c|c|c|c|c|c|c|}
\hline \multirow[t]{2}{*}{ Traits } & \multicolumn{2}{|c|}{ Group 1} & \multicolumn{2}{|c|}{ Group 2} & \multicolumn{2}{|c|}{ Group 3} & \multicolumn{2}{|c|}{ Group 4} & \multicolumn{2}{|c|}{ Group 5} & \multicolumn{2}{|l|}{ Group 6} & \multicolumn{2}{|c|}{ Group 7} \\
\hline & Mean & SD & Mean & SD & Mean & SD & Mean & SD & Mean & SD & Mean & SD & Mean & SD \\
\hline Days to flower initiation & 62.38 & 10.51 & 74.40 & 12.92 & 61.00 & 0.00 & 55.67 & 10.11 & 63.11 & 8.08 & 74.43 & 13.64 & 77.21 & 15.30 \\
\hline Days to $50 \%$ flow & 78.50 & 9.39 & 91.20 & 11.95 & 90.00 & 2.83 & 74.50 & 10.78 & 79.70 & 8.52 & 84.29 & 14.12 & 110.00 & 14.10 \\
\hline Days to flower completion & 0.25 & 10.37 & 106.80 & 12.07 & 116.00 & 1.41 & 90.33 & 14.22 & 94.83 & 11.82 & 108.52 & 15.04 & 122.11 & 15.00 \\
\hline Days to maturity & 163.25 & 3.61 & 165.20 & 3.27 & 163.50 & 3.54 & 165.67 & 2.94 & 168.27 & 4.69 & 165.71 & 3.87 & 188.20 & 13.21 \\
\hline Leaf 1 & .49 & 4.21 & 1.34 & 2.79 & 9.45 & 0.78 & 20.08 & 9.78 & 17.66 & 4.99 & 20.70 & 5.45 & 14.01 & 12.22 \\
\hline Leaf 1 & 66 & 10.28 & 2.56 & 5.20 & 1.10 & 17.54 & 48.75 & 11.62 & 44.12 & 8.58 & 44.73 & 8.28 & 39.22 & 13.21 \\
\hline Leaf width & .59 & 12.30 & 14.74 & 1.78 & 14.45 & 1.91 & 13.92 & 4.51 & 15.17 & 3.84 & 17.09 & 10.36 & 17.78 & 14.44 \\
\hline Leaf length per width ratio & 2.56 & 0.76 & 3.58 & 0.34 & 2.09 & 0.94 & 3.67 & 0.72 & 3.02 & 0.60 & 2.93 & 0.73 & 2.44 & 0.73 \\
\hline Leaves per plant & 1.19 & 3.10 & 17.80 & 3.27 & 24.00 & 1.41 & 18.50 & 4.23 & 20.20 & 3.53 & 18.86 & 2.63 & 24.6 & 13.29 \\
\hline Plant $h$ & 25.31 & 17.36 & 201.80 & 8.32 & 237.00 & 5.66 & 227.33 & 16.60 & 228.95 & 15.44 & 228.71 & 21.05 & 250.1 & 17.77 \\
\hline es per plant & 1.00 & 2.16 & 11.40 & 1.82 & 13.00 & 1.41 & 13.33 & 1.63 & 12.39 & 2.33 & 11.57 & 2.58 & 10.90 & 2.22 \\
\hline & .69 & 15.93 & 81.60 & 7.50 & 3.50 & 14.85 & 79.33 & 7.79 & 78.70 & 8.49 & 71.95 & 14.97 & 69.32 & 14.87 \\
\hline Silic & 76.00 & 10.84 & 79.60 & 9.21 & 92.00 & 4.24 & 79.67 & 20.34 & 70.45 & 13.52 & 72.76 & 17.43 & 64.45 & 11.21 \\
\hline Siliq & 6.36 & 1.10 & 6.18 & 0.79 & 6.55 & 0.92 & 5.20 & 0.97 & 6.27 & 0.88 & 6.28 & 0.68 & 6.23 & 2.11 \\
\hline Siliqu & 0.47 & 0.05 & 0.46 & 0.04 & 0.45 & 0.01 & 0.47 & 0.08 & 0.47 & 0.07 & 0.49 & 0.05 & 0.44 & 0.03 \\
\hline Siliq & .69 & 2.31 & 13.69 & 2.85 & 14.59 & 2.50 & 11.09 & 1.71 & 13.57 & 2.18 & 12.98 & 1.97 & 11.78 & 2.98 \\
\hline & .25 & 3.42 & 25.00 & 1.58 & 29.00 & 1.41 & 22.33 & 7.71 & 26.30 & 3.25 & 25.24 & 2.77 & 23.22 & 3.80 \\
\hline & .96 & 17.68 & 44.24 & 9.51 & 90.05 & 26.38 & 48.75 & 15.37 & 49.97 & 12.01 & 53.39 & 16.64 & 46.99 & 18.11 \\
\hline & & 0.82 & 3.96 & 0.68 & & 0.42 & 3.38 & 1.0 & 2.98 & 0.81 & 3. & 1. & 2.90 & 0.80 \\
\hline & .89 & 2.46 & 45.94 & 1.16 & 42.35 & 2.33 & 46.73 & 1.82 & 47.31 & 3.00 & 46.93 & 2.06 & 41.0 & 21.34 \\
\hline Prote & 26.00 & 2.33 & 26.08 & 0.80 & 27.35 & 1.91 & 24.15 & 2.13 & 23.93 & 2.24 & 24.49 & 1.80 & 22.10 & 20.00 \\
\hline Gluce & 07.33 & 23.34 & 143.66 & 5.35 & 97.00 & 20.36 & 79.97 & 19.79 & 83.53 & 22.40 & 89.92 & 14.07 & 118.00 & 9.91 \\
\hline Oleic a & 42.23 & 7.08 & 34.00 & 1.97 & 42.00 & 1.84 & 52.90 & 4.39 & 50.34 & 6.06 & 48.22 & 5.68 & 39.43 & 5.99 \\
\hline Linoleic acid & 10.21 & 1.26 & 11.24 & 1.11 & 12.10 & 3.82 & 8.42 & 0.87 & 8.28 & 1.39 & 8.80 & 1.01 & 11.26 & 1.00 \\
\hline Erucic acid & 51.81 & 7.25 & 59.90 & 0.61 & 31.35 & 22.70 & 48.00 & 16.06 & 48.22 & 8.15 & 48.90 & 9.59 & 55.45 & 8.90 \\
\hline
\end{tabular}

Clusters (genotypes from those clusters) can only be related to geographical origin if their natural habitats differ so that the selective pressure forced populations to adapt in different directions. A total of 169 B. napus L. lines were genotyped with 84 SSR markers, and Nei's unbiased genetic diversity and Shannon's information index showed that genetic diversity was highest among lines from Europe followed by South Korea, Japan, China and Pakistan while lines from Australia and Canada had the lowest diversity (Gyawali et al., 2013; Jankulovska et al., 2014).

In present studies, principal component analysis of $B$. napus L. accessions revealed grouping relationship differently, and indirectly supported cluster analysis. The separation of genotypes based on PC1 and PC2 revealed that the populations were distributed in all the directions, which clearly recognized the diversification in indigenous landraces of B. napus L. Previous data based on first and second five PCs with $>1$ contributed $73.30 \%$ and $64.45 \%$ of the genetic variability, respectively among various accessions of B. juncea L. (Ali et al., 2015). Past researchers have made divergence studies of morphological and seed attributes using principal component and cluster analyses in Brassica species (Takahata and Hinata, 1986), B. napus L. (Bus et al., 2011; Gyawali et al., 2013), Indian mustard (Dias et al., 1993; Rabbani et al., 1998b), Ethiopian mustard (Alemayehu and Becker, 2002; Genet et al., 2005; Warwick et al., 2006), and white head cabbage (Balkaya et al., 2005). However, the present two methods i.e., cluster and principal component analyses were found more appropriate and can better dig out the relationship between the genotypes of assorted origins.

\section{Conclusion}

Seventy landraces of B. napus L. revealed significant genetic variability for majority traits during both years of studies. Among B. napus L. germplasm, the prime genetic variability producing traits were, plant height and time to maturity, while sufficient variations were recorded for flower initiation and completion, main raceme length and silique per main raceme and glucosinolate content. During 2012 and 2013, cluster analysis divided the total 70 landraces of $B$. napus into nine and seven main groups, respectively and contribution of five principal components.

\section{References}

Abideen, S.N.U., F. Nadeem and S.A. Abideen, 2013.Genetic variability and correlation studies in B. napus L. genotypes. Int. J. Innov. Appl. Stud., 2: 574-581

Akbar, F., M.A. Rabbani, Z.K. Shinwari and S.J. Khan, 2011. Genetic divergence in sesame ( $S$. indicum L.) landraces based on qualitative and quantitative traits. Pak. J. Bot., 43: 2737-2744

Alemayehu, N. and H. Becker, 2002.Genotypic diversity and patterns of variation in a germplasm material of Ethiopian mustard (B. carinata A. Braun). Genet. Resour. Crop Evol., 49: 573-582

Ali, M., L.O. Copeland, S.G. Elias and J.D. Kelly, 1995. Relationship between genetic distance and heterosis for yield and morphological traits in winter canola (B. napus L.). Theor. Appl. Genet., 91: 118-121

Ali, N., Farhatullah, J. Bakht, M.A. Rabbani and A. Khan, 2015. Estimation of variability among indigenous $B$. juncea $\mathrm{L}$. accessions based on morphological and biochemical characteristics. Pak. J. Agric. Sci., 52: $63-71$

Amurrio, J.M., A.A. de-Ron and A.C. Zeven, 1995. Numerical taxonomy of Iberian pea landraces based on quantitative and qualitative characters. Euphytica, 82: 195-205 
Arslanoglu, F., S. Aytac and K. Oner, 2011. Morphological characterization of the local potato (S. tuberosum L.) genotypes collected from the Eastern Black Sea region of Turkey. Afr. J. Biotechnol., 10: 922-932

Balkaya, A., R. Yanmaz, A. Apaydin and H. Kar, 2005. Morphological characterization of white head cabbage (B. oleraceavar. capitatasubvar. alba) genotypes in Turkey. N.Z. J. Crop Hortic. Sci., 33: 333-341

Bus, A., N. Korber, R.J. Snowdon and B. Stich, 2011. Patterns of molecular variation in a species-wide germplasm set of B. napus. Theor. Appl. Genet.,123: 1413-1423

Cartea, M.E., A. Picoaga, P. Soengas and A. Ordas, 2003. Morphological characterization of kale populations from northwestern Spain. Euphytica, 129: 25-32

Chauhan, J.S., V.P.S. Bhadauria, K.H. Singh, S. Maharaj and K. Arvind, 2008. Genetic diversity analysis in rapeseed-mustard using quality characteristics. Ann. Arid Zone, 47: 145-149

Chen, B.Y., W.K. Heneen and R. Jonsson, 1988. Independent inheritance of erucic acid content and flower color in the $\mathrm{C}$-genome of B. napus $\mathrm{L}$. Plant Breed., 100: 147-149

Dhillon, S.S., K. Singh and K.S. Barar, 1999. Diversity analysis of highly selected genotypes in Indian mustard (B. juncea Czern \& Coss). $10^{\text {th }}$ Int. Rapeseed Cong. Sep. 26-29, Canberra, Australia

Dias, J.S., A.A. Monteiro and M.B. Lima, 1993. Numerical taxonomy of Portuguese tronchuda cabbage and galega kale landraces using morphological characters. Euphytica, 69: 51-68

Genet, T., M.T. Labuschagne and A. Hugo, 2005. Genetic relationships among Ethiopian mustard genotypes based on oil contents and fatty acid composition. Afr. J. Biotechnol., 4: 1256-1268

Gomez, K.A. and A.A. Gomez, 1984. Statistical Procedures for Agricultural Research, $2^{\text {nd }}$ edition. John Willey \& Sons, Inc., New York, USA

Gupta, S.K. and A. Pratap, 2007. Phenotypic stability of Indian mustard (B. juncea $\mathrm{L}$. Czerm and coss) genotypes developed from inter-varietal and intergeneric crosses. Ind. J. Crop Sci., 2: 379-382

Gyawali, S., D.D. Hegedus, I.A.P. Parkin, J. Poon, E. Higgins, K. Horner, D. Bekkaoui, C. Coutu and L. Buchwaldt, 2013. Genetic diversity and population structure in a world collection of Brassica napus accessions with emphasis on South Korea, Japan, and Pakistan. Crop Sci., 53: 1537-1545

Hasan, M., F. Seyis, A.G. Badani, J. Pons-Kuhnemann, W. Friedt, W. Luhs and R.J. Snowdon, 2006. Analysis of genetic diversity in the $B$. napus gene pool using SSR markers. Genet. Res. Crop Evol., 53 793-802

Hu, S., C. Yu, H. Zhao, G. Sun, S. Zhao, M. Vyvadilova and V. Kucera, 2007. Genetic diversity of B. napus L. germplasm from China and Europe assessed by some agronomically important characters. Euphytica, 154: 9-16

Islam, M.S. and M.O. Islam, 2000. Genetic diversity in rapeseed and mustard (Brassica sp.). Bangl. J. Genet. Plant Breed., 13: 25-30

Jankulovska, M., S. Ivanovska, A.J. Marjanovic, S. Bolaric, L. Jankuloski, Z. Dimov, D. Bosev and B. Kuzmanovska, 2014. Multivariate analysis of quantitative traits can effectively classify rapeseed germplasm. Genetika, 46: 545-559

Jatoi, S.A., A. Javaid, M. Iqbal, O.U. Sayal, M.S. Masood and S.U. Siddiqui, 2011. Genetic diversity in radish germplasm for morphological traits and seed storage proteins. Pak. J. Bot., 43: 2507-2512
Khan, M.H., M.M. Ali, S.R. Vuiyan and F. Mahmud, 2013. Genetic divergence in rapeseed-mustard (B. rapa L.). Bangl. J. Agric. Res., 38: $417-423$

Kimber, D.S. and D.I. McGregor, 1995. The species and their origin, cultivation and world production. In: Brassica Oilseed; Production and Utilization, pp: 1-7. Kimber, D.S. and D.I.McGregor (eds.). Centre for Agric. and Biosci. Int. University Press, Cambridge, UK

Love, C.G., A.J. Robinson, G.A. Lim, C.J. Hopkins, J. Batley, G. Barker, G.C. Spangenberg and D. Edwards, 2005. Brassica ASTRA: an integrated database for Brassica genomic research. Nucl. Acids Res., 33: 656-659

Mohammadi, S.A. and B.M. Prasanna, 2003. Analysis of genetic diversity in crop plants salient statistical tools and considerations. Crop Sci., 43: $1235-1248$

Padilla, G., M.E. Cartea, P. Velasco, A. Haro and A. Ordas, 2007. Variation of glucosinolates in vegetable crops of B. rapa. Phytochemistry, 68 : $536-545$

Padilla, G., M.E. Cartea, V.M. Rodríguez and A. Ordas, 2005. Genetic diversity in a germplasm collection of $B$. rapa subsp. rapa $\mathrm{L}$. from Northwestern Spain. Euphytica, 145: 171-180

Rabbani, M.A., A. Iwabuchi, Y. Murakami, T. Suzuki and K. Takayanagi, 1998a. Genetic diversity in mustard (B. juncea L.) germplasm from Pakistan as determined by RAPDs. Euphytica, 103: 235-242

Rabbani, M.A., A. Iwabuchi, Y. Murakami, T. Suzuki and K. Takayanagi, 1998b. Phenotypic variation and the relationships among mustard (B. juncea L.) germplasm from Pakistan. Euphytica, 101: 357-366

Rich, T.C.G., 1991. Crucifers of Great Britain and Ireland, p: 336. Botanical Society of the British Isles, London

Rodriguez, V.M., M.E. Cartea, G. Padilla, P. Velasco and A. Ordas, 2005. The Nabicol: a horticultural crop in Northwestern Spain. Euphytica, 142: 237-246

Rohlf, F.J., 2002. NTSYS-PC: Numerical Taxonomy and Multivariate Analysis System, Version 2.01. Exeter Publishing Ltd., Setauket, New York, USA

Sneath, P.H.A. and R.R. Sokal, 1973. Numerical Taxonomy, pp: XV + 573. The principle and practices of numerical classification. W.H. Freeman and Company, San Francisco, USA

Takahata, Y. and K. Hinata, 1986. A consideration of the species relationships in sub-tribe Brassicinae (Cruciferae) in view of cluster analysis of morphological characters. Plant Sp. Biol., 1: 79-88

Thompson, J.A., R.L. Nelson and L.O. Vodkin, 1998. Identification of diverse soybean germplasm using RAPD markers. Crop Sci., 38: 1348-1355

Turi, N.A., Farhatullah, M.A. Rabbani and Z.K. Shinwari, 2012. Genetic diversity in the locally collected Brassica species of Pakistan based on microsatellite markers. Pak. J. Bot., 44: 1029-1035

Warwick, S.I., R.K. Gugel, T. Mcdonald and K.C. Falk, 2006. Genetic variation of Ethiopian mustard (B. carinata L.) germplasm in western Canada. Genet. Resour. Crop Evol., 53: 297-312

Yousaf, M., S.U. Ajmal, M. Munir and A. Ghafoor, 2011. Genetic diversity analysis for gro-morphological and seed quality traits in rapeseed $(B$. campestris L.). Pak.J. Bot., 43: 1195-1203

Zada, M., N. Zakir, M.A. Rabbani and Z.K. Shinwari, 2013. Assessment of genetic variation in ethiopian mustard (B. carinata Braun) germplasm using multivariate techniques. Pak. J. Bot., 45: 583-593

(Received 20 May 2017; Accepted 25 September 2017) 